\title{
Effects of Volume Fraction and Carbon Concentration of Austenite on Formation of Ultrafine Grained Ferrite/Austenite Duplex Microstructure by Warm Compression
}

\author{
Pingguang $\mathrm{XU}{ }^{1)}$ Jianhong $\mathrm{LI}^{11}{ }^{1)}$ Yo TOMOTA ${ }^{11}$ and Yoshitaka ADACH ${ }^{21}$ \\ 1) Graduate School of Science and Engineering, Ibaraki University, Hitachi, Ibaraki 316-8511 Japan. \\ 2) Innovative Materials Engineering Laboratory, National Institute for Materials Science, Tsukuba, Ibaraki $305-0047$ Japan.
}

(Received on April 23, 2008; accepted on August 27, 2008)

\begin{abstract}
The microstructures of two high-nickel martensite steels with different carbon contents before and after warm compression were comparably investigated by using a field-emission scanning electron microscope attached with an electron backscattering diffraction equipment (FE-SEM/EBSD) and a transmission electron microscope attached with an energy dispersive X-ray spectroscope (TEM/EDX). The microstructure observations suggest that the carbon addition is beneficial to reduce the critical strain for full recrystallization during warm compression and the increment of carbon-enriched austenite amount accelerates the dynamic recrystallization of ferrite through plastic deformation partitioning in the $17 \mathrm{Ni}-0.2 \mathrm{C}$ martensite steel. Proper pretempering promotes the precipitation of the carbon- and nickel-enriched austenite, and then promotes the dynamic recrystallization. On the other hand, long-time tempering leads to the carbon depletion in austenite so as to delay the dynamic recrystallization. The full recrystallization of the $18 \mathrm{Ni}$ martensite steel takes place at a higher strain during warm compression, mainly because of no carbon-enriched austenite.
\end{abstract}

KEY WORDS: grain refinement; dynamic recrystallization; warm deformation; dynamic precipitation; martensite; austenite.

\section{Introduction}

Many researches have been made to obtain various ultrafine grained microstructures with a favorable strengthtoughness balance so far. In the investigation of thermomechanically controlled processing (TMCP), dynamic recrystallization was found in austenite steels. It was also confirmed in ferritic stainless steels deformed at elevated temperatures. ${ }^{1-4)}$ However, this technology was not applied to produce low alloy steel plates because it required severe deformation with a high Zener-Hollomon parameter $(Z=$ $\dot{\varepsilon} \cdot \exp (Q / R T)$, where, $\dot{\varepsilon}, Q, R$ and $T$ were the strain rate, the activation energy, the gas constant and the absolute temperature, respectively). In recent years, Torizuka et al. ${ }^{5)}$ applied high $Z$-value warm deformation to ferrite-pearlite steels and obtained a submicron-sized ferrite-cementite structure at a true strain of $\varepsilon \geq 2.0$. In contrast to the conventional discontinuous dynamic recrystallization, such microstructure evolution during the high $Z$-value warm deformation is called continuous dynamic recrystallization, i.e. the initial grains are divided by sub-boundaries which finally evolve into high angle boundaries during the deformation. Similar phenomenon was reported for the accumulative roll-bonding (ARB) of IF steel. ${ }^{6}$

Martensite structure has been pointed out to be a suitable initial microstructure to obtain fine grained ferrite or duplex microstructures. In 1972, Miller ${ }^{7}$ found that ultrafine ferrite-austenite structures can be easily obtained by cold rolling followed by annealing for $\mathrm{Ni}(-\mathrm{Mn})-\mathrm{C}$ steels. Ameyama et al. $^{8)}$ studied non-tempered low carbon steels and tempered medium carbon steels and claimed that the competition of austenite precipitation and ferrite recrystallization plays an important role to obtain ultrafine grained structures. Ueji et al. ${ }^{9)}$ showed that the initial fine structures and high dislocation density of martensite are helpful to accelerate the recrystallization during annealing of cold rolled martensite steel.

Warm deformation of martensite is postulated to be promising as an industrial application. Hayashi et al. ${ }^{10)}$ reported that the ultrafine grained ferrite-cementite structure (about $0.93 \mu \mathrm{m}$ ) can be obtained by the multi-pass groove rolling of SM490 martensite steel with $85 \%$ accumulated reduction at $913 \mathrm{~K}$. Bao et al. ${ }^{11,12)}$ found that the dynamic recrystallization took place in $18 \mathrm{Ni}, 17 \mathrm{Ni}-0.2 \mathrm{C}$, and SM490 martensite steels during the warm compression at a smaller strain than in ferrite-pearlite steels. The comparable investigation among pearlite, ferrite-spheroidized cementite, and tempered martensite as initial microstructures ${ }^{13)}$ showed that the tempered martensite is much easier to result in ultrafine grained ferrite-cementite structure by warm deformation. Li et al. ${ }^{14)}$ reported that the initial martensite block size and compression amount have little influence on the grain size of fully recrystallized ferrite. Poorganji et $a l .{ }^{15)}$ found that the increment of carbon concentration in martensite steels could refine the fully recrystallized ferrite grains by warm deformation. 

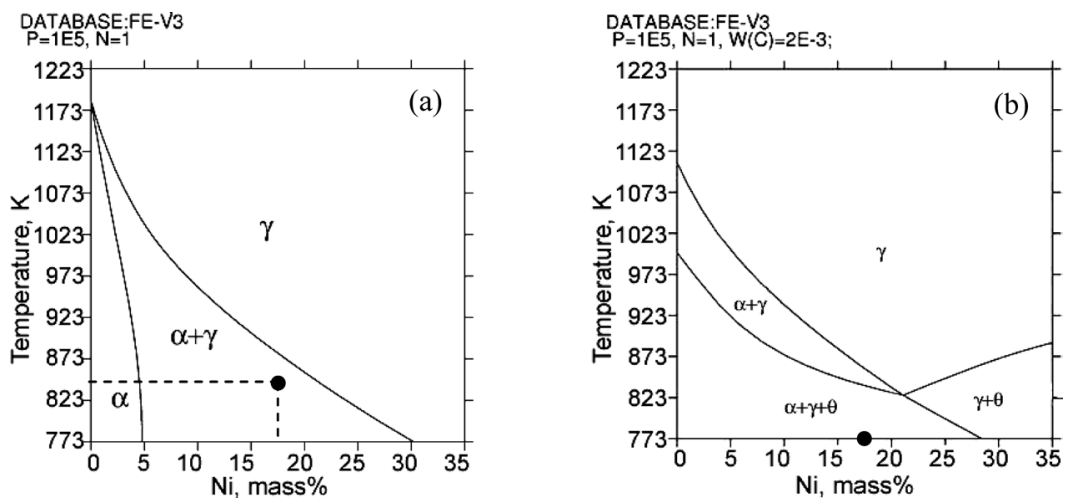

Fig. 1. Equilibrium phase diagrams for (a) $\mathrm{Fe}-\mathrm{Ni}$ and (b) $\mathrm{Fe}-\mathrm{Ni}-0.2 \mathrm{mass} \% \mathrm{C}$ systems calculated by using the THERMOCALC Fe-DATA (Ver. 3) database.

Because the austenite in low alloy steels can evidently improve the tensile ductility through the transformation induced plasticity (TRIP) effect ${ }^{16)}$, ultrafine grained austenite-ferrite duplex microstructures have attracted much attention. ${ }^{17)}$ It is important to make clear the role of austenite and its stability depending on carbon concentration for realizing ultrafine grained ferrite-austenite steels. However, there is no report to study the effect of austenite on the dynamic recrystallization of ferrite during warm compression. In this paper, the effects of austenite precipitation and the carbon enrichment/depletion in austenite on the dynamic recrystallization during warm compression were investigated by using two high-nickel martensite steels with different carbon contents through microstructure observations. Considering that the neutron diffraction has been employed as a powerful technique for in situ materials characterization, ${ }^{18,19)}$ in another complementary paper, ${ }^{20)}$ the warm deformation and dynamic recrystallization behaviors of the carbon-added high-nickel martensite steel were in situ investigated by neutron diffraction to make clear the grain refinement mechanism and the related crystallographic evaluation data were reported.

\section{Experimental Procedures}

The chemical compositions of two investigated steels, $18 \mathrm{Ni}$ and $17 \mathrm{Ni}-0.2 \mathrm{C}$, were given in Table 1 . The $15 \times 15$ $\mathrm{mm}$ steel bars were solution treated at $1373 \mathrm{~K}$ for $1.8 \mathrm{ks}$ followed by water quenching. According to the phase diagrams of $\mathrm{Fe}-\mathrm{Ni}$ and $\mathrm{Fe}-\mathrm{Ni}-\mathrm{C}$ alloys (Fig. 1), $843 \mathrm{~K}$ and $773 \mathrm{~K}$ were chosen as the pre-tempering temperature of $18 \mathrm{Ni}$ and $17 \mathrm{Ni}-0.2 \mathrm{C}$ steels, respectively. Cylindrical samples of $6.5 \mathrm{~mm}$ in length and $4 \mathrm{~mm}$ in diameter for compression tests were prepared by spark cutting and surface grinding. The samples were heated up to the deformation temperature at a heating rate of $5 \mathrm{~K} / \mathrm{s}$ and then deformed at $8.3 \times 10^{-4} /$ s followed by water quenching (see Fig. 2).

The longitudinally sectioned specimens were polished in an electrochemical solution with $5 \% \mathrm{HClO}_{4}$ and $95 \%$ $\mathrm{CH}_{3} \mathrm{COOH}$ to avoid the stress induced martensite transformation of austenite at the surface. The microstructure orientation characteristics were measured at $25 \mathrm{kV}$ with a Hitachi S-4300SE field-emission scanning electron microscope (SEM) by using the electron backscattering diffraction (EBSD) technique and the results from at least two dif-
Table 1. Chemical compositions of investigated steels (mass\%).

\begin{tabular}{cccccc}
\hline Symbol & $\mathrm{C}$ & $\mathrm{Mn}$ & $\mathrm{Si}$ & $\mathrm{Ni}$ & $\mathrm{Nb}$ \\
\hline $18 \mathrm{Ni}$ & 0.003 & $<0.01$ & $<0.01$ & 17.96 & 0.002 \\
$17 \mathrm{Ni}-0.2 \mathrm{C}$ & 0.22 & $<0.01$ & $<0.01$ & 17.2 & 0.002 \\
\hline
\end{tabular}
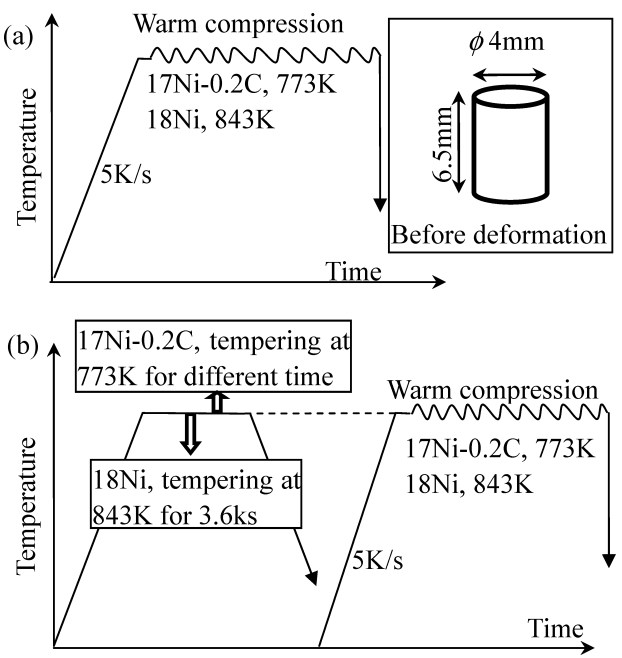

Fig. 2. Illustrations for deformation processes of investigated martensite steels: (a) without pre-tempering; (b) with pretempering for different times.

ferent image fields were averaged to improve the data reliability. Considering the change in grain shapes of various microstructures, grain size distributions were statistically analyzed on EBSD orientation maps using the area fraction method.

In order to confirm the static/dynamic precipitation of small austenite/cementite particles and the dynamic recrystallization of ferrite, the substructure observation, the Kikuchi pattern analysis and the selected area diffraction analysis were carried out using a JEM 2010 transmission electron microscope (TEM) operated at $200 \mathrm{kV}$. The chemical compositions of the second phase and the ferrite matrix were analyzed with an attached TN5500 energy dispersive X-ray spectrometer (EDX) by using the Standard-free Metallurgical Thin Films Correction Program (SMTF). The foil samples after grinding to less than $100 \mu \mathrm{m}$ in thickness were twin-jet polished in the $5 \% \mathrm{HClO}_{4}$ and $95 \%$ $\mathrm{CH}_{3} \mathrm{COOH}$ solution at room temperature and in the $5 \%$ 
$\mathrm{HClO}_{4}$ and $95 \% \mathrm{CH}_{3} \mathrm{OH}$ solution at $223 \mathrm{~K}$.

\section{Results and Discussion}

\subsection{SEM Microstructure Observation}

Because the warm compression at different deformation temperatures results in different Zener-Hollomon parameters for two investigated steels $(17 \mathrm{Ni}-0.2 \mathrm{C}, 773 \mathrm{~K}$, $Z=1.21 \times 10^{14} \mathrm{~s}^{-1} ; 18 \mathrm{Ni}, 843 \mathrm{~K}, Z=4.55 \times 10^{12} \mathrm{~s}^{-1}$ ), it is necessary to compare the warm compressed specimens at the same deformation temperature. Figure 3 provides a group of SEM microstructures of differently pre-tempered $17 \mathrm{Ni}-0.2 \mathrm{C}$ specimens before and after warm compression at $773 \mathrm{~K}$ where the compression axis (c.a.) is along the vertical direction (same in the following figures). Different from the non-tempered martensite (Fig. 3(a)), small particles can be found in the tempered martensite matrix (marked by circles in Fig. 3(b)), and these particles are coarser (marked by circles in Fig. 3(c)) after long-time pre- tempering. In the warm deformed specimen at $773 \mathrm{~K}$ without pre-tempering, ultrafine equiaxed grains (marked by white arrows) predominate the SEM microstructure while some elongated grains (marked by gray arrows) related to recovery can also be found. In contrast, the warm deformed specimen with $3.6 \mathrm{ks}$ pre-tempering shows a fully equiaxed microstructure, and the ferrite grains are much finer. In case of the $36 \mathrm{ks}$ tempered specimen, the same warm compression results in a partially equiaxed microstructure, which suggests that the long-time pre-tempering retards the ferrite recrystallization evidently and a large compressive strain is necessary to achieve full recrystallization.

Considering that Bao et al. ${ }^{12)}$ have observed the SEM microstructures of non-tempered martensite steels after warm compression systematically, Figure 4 shows typical microstructures of $18 \mathrm{Ni}$ and $17 \mathrm{Ni}-0.2 \mathrm{C}$ steels with $3.6 \mathrm{ks}$ pretempering treatment at different warm compressive strains. It is clear that the martensite block width of $17 \mathrm{Ni}-0.2 \mathrm{C}$ steel is narrower than that of $18 \mathrm{Ni}$ steel. After a compres-

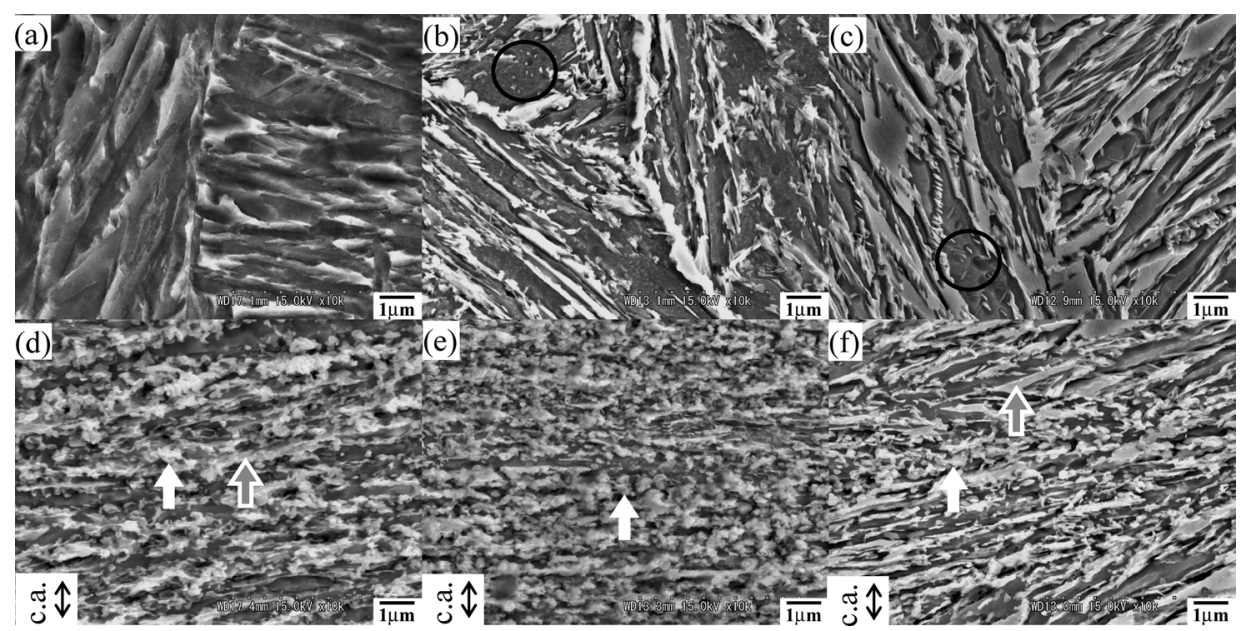

Fig. 3. SEM microstructures of different pre-tempered specimens of $17 \mathrm{Ni}-0.2 \mathrm{C}$ steel before $(\mathrm{a}, \mathrm{b}$ and $\mathrm{c}$ ) and after (d, e and f) warm compression at $773 \mathrm{~K}, \varepsilon=0.6,8.3 \times 10^{-4} / \mathrm{s}$, where the compression axis is along the vertical direction. The elongated grains and the equiaxed grains are marked by gray and white arrows, respectively: (a, d) nontempered; (b, e) $3.6 \mathrm{ks}$ tempered; (c, f) 36.0 ks tempered.

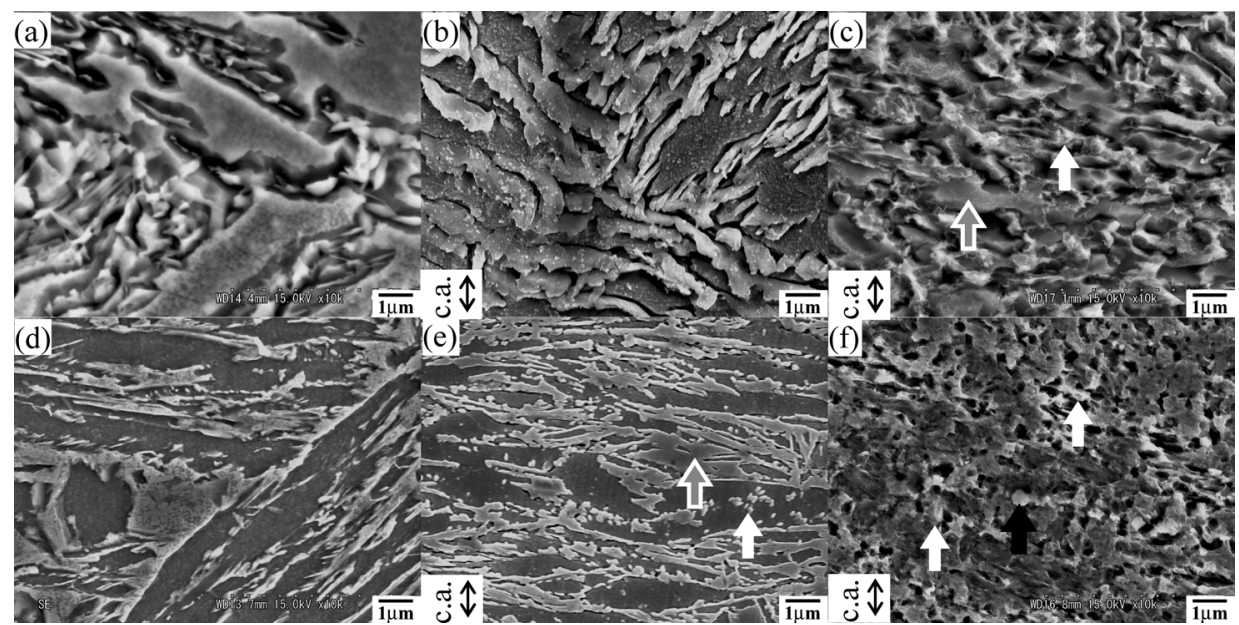

Fig. 4. SEM microstructures of warm compressed martensite steels with $3.6 \mathrm{ks}$ pre-tempering. Here the compression axis is along the vertical direction, the elongated grains and the equiaxed grains are marked by gray and white arrows, respectively: (a) $18 \mathrm{Ni}$, no deformation; (b) $18 \mathrm{Ni}$ at $843 \mathrm{~K}, 8.3 \times 10^{-4} / \mathrm{s}, \varepsilon=0.27$, few equiaxed grains; (c) $18 \mathrm{Ni}$ at $843 \mathrm{~K}, 8.3 \times 10^{-4} / \mathrm{s}, \varepsilon=0.6$, partially equiaxed grains; (d) $17 \mathrm{Ni}-0.2 \mathrm{C}$, no deformation; (e) $17 \mathrm{Ni}-0.2 \mathrm{C}$ at $773 \mathrm{~K}$, $8.3 \times 10^{-4} / \mathrm{s}, \varepsilon=0.27$, partially equiaxed grains; (f) $17 \mathrm{Ni}-0.2 \mathrm{C}$ at $773 \mathrm{~K}, 8.3 \times 10^{-4} / \mathrm{s}, \varepsilon=0.6$, fully equiaxed grains. 


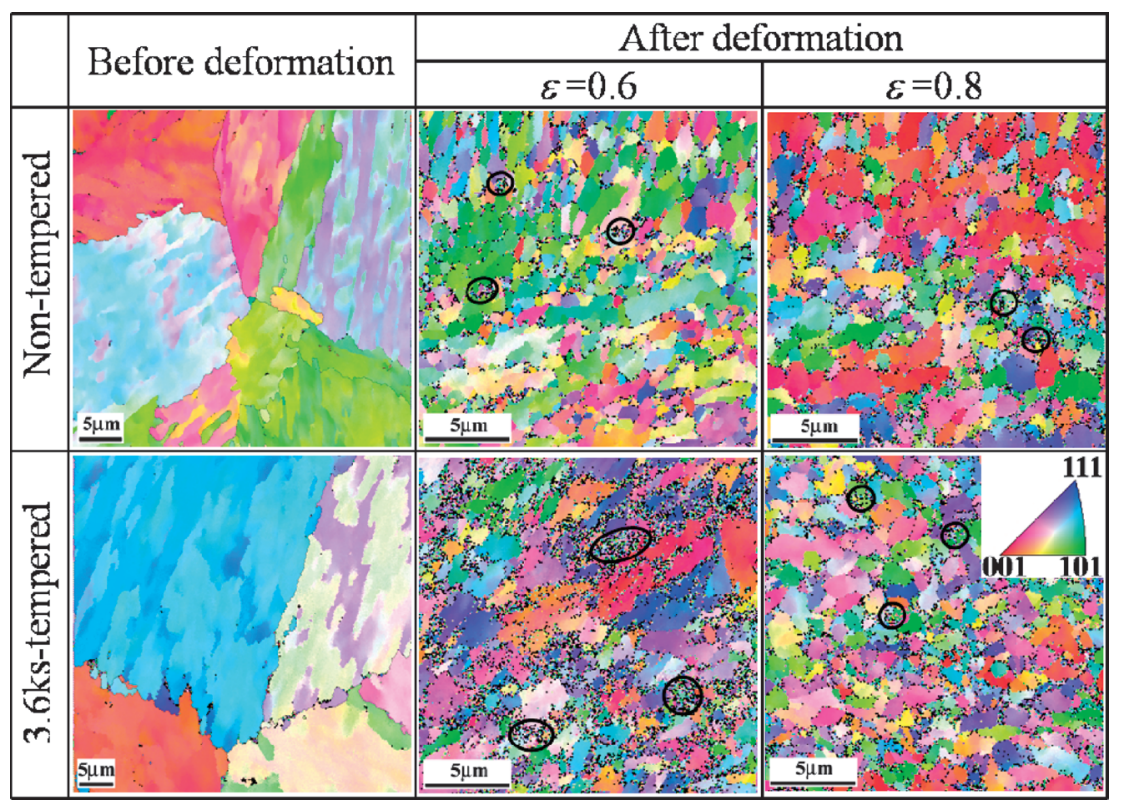

Fig. 5. Crystallographic orientation characteristics of $18 \mathrm{Ni}$ martensite steel before and after warm compression at $843 \mathrm{~K}$, $8.3 \times 10^{-4} / \mathrm{s}$. The compression axis is along the vertical direction.

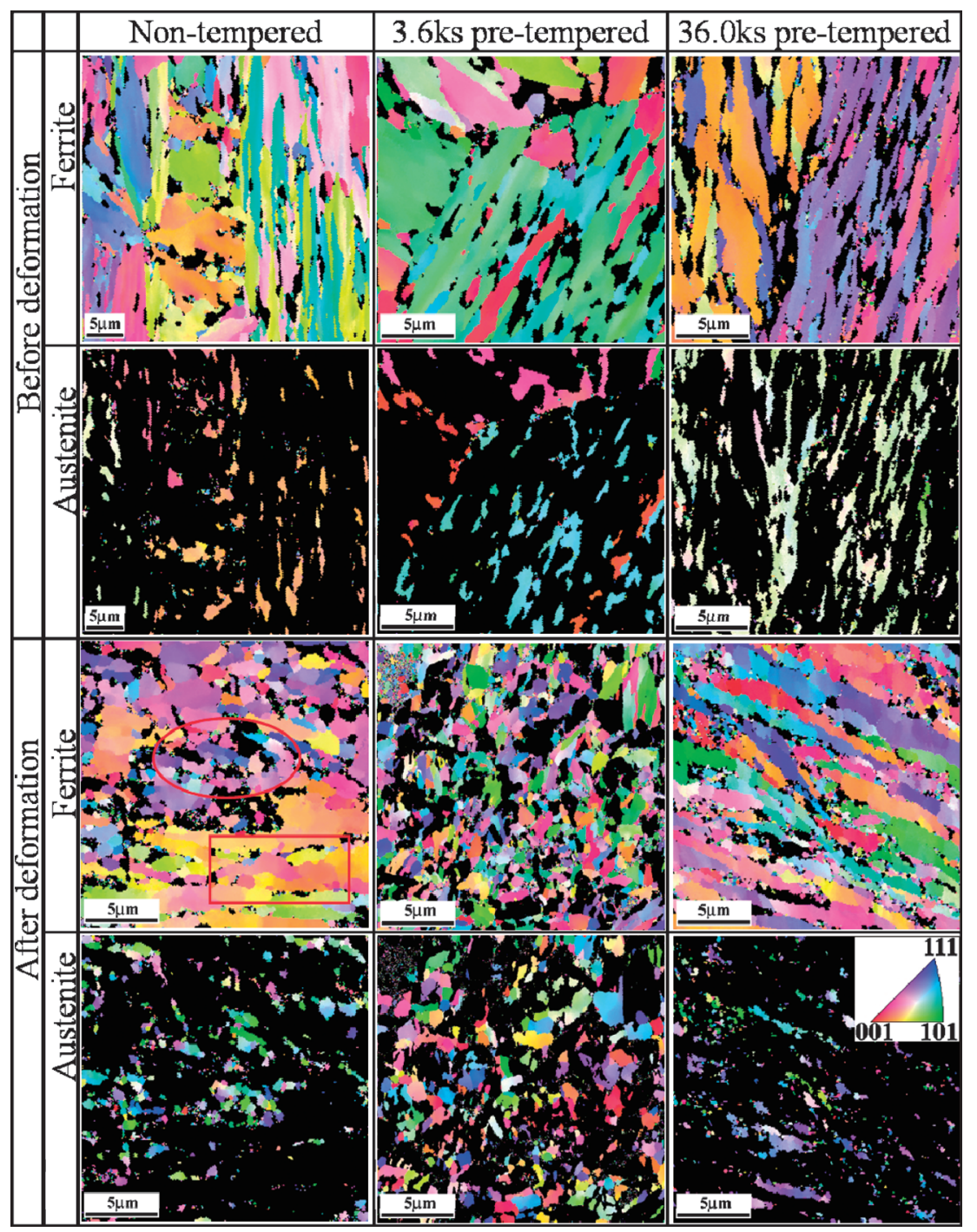

Fig. 6. Crystallographic orientation characteristics of different pre-tempered $17 \mathrm{Ni}-0.2 \mathrm{C}$ martensite steel specimens before and after warm compression at $773 \mathrm{~K}, 8.3 \times 10^{-4} / \mathrm{s}$. The compression axis is along the vertical direction. 
sive deformation of $\varepsilon=0.27$, few equiaxed grains related to recrystallization appear in the $18 \mathrm{Ni}$ steel (Fig. 4(b)). In the $17 \mathrm{Ni}-0.2 \mathrm{C}$ steel, however, ultrafine equiaxed grains can be observed frequently (Fig. 4(e)). The elongated grains exist in the $18 \mathrm{Ni}$ steel even after a warm compression of $\varepsilon=0.6$ (Fig. 4(c)), which suggests that a little larger strain is necessary to realize the full recrystallization. For the $17 \mathrm{Ni}-0.2 \mathrm{C}$ steel at $\varepsilon=0.6$, the fully equiaxed microstructure reveals that the high carbon content is beneficial to the dynamic recrystallization.

\subsection{EBSD Microstructure Characterization}

Figure 5 shows the crystallographic orientation characteristics of $18 \mathrm{Ni}$ steel microstructures before and after warm deformation. The volume fraction of retained austenite in the non-tempered microstructure is less than $1 \%$, and the austenite amount increases hardly by the $3.6 \mathrm{ks}$ pre-tempering treatment. In the $\varepsilon=0.6$ warm compressed specimen without pre-tempering, the equiaxed grains are dominative in the ferrite matrix even though lots of grains are still with small misorientation; in case of $3.6 \mathrm{ks}$ pre-tempering, the amount of equiaxed ferrite grains is less and the average grain size is a little coarser (Table 2), suggesting that the decrease in dislocation density in the initial microstructure by pre-tempering brings negative influence on the dynamic recrystallization. After a larger strain warm compression ( $\varepsilon=0.8$ ), the fully equiaxed ferrite grains can be obtained in both cases and their average grain sizes (about $1.30 \mu \mathrm{m}$ and $1.19 \mu \mathrm{m})$ are approximately equal. Although blocky austenite grains are not observed in the microstructures after warm compression, the local regions with a confidence index of less than 0.2 (marked by circles in Fig. 5) are likely to be the metastable austenite. As would be discussed later, most of the austenite grains formed during warm compression transformed to martensite upon cooling.

Figure 6 gives the crystallographic orientation maps of $17 \mathrm{Ni}-0.2 \mathrm{C}$ microstructures before and after warm compression. The austenite volume fraction is plotted in Fig. 7. For the non-tempered specimens, the austenite volume fraction increases from $9.5 \%$ before deformation to $17 \%$ after deformation and the average grain size of austenite decreases from 1.83 to $0.62 \mu \mathrm{m}$ (Table 2), which is related to the precipitation of ultrafine grained austenite during warm deformation. After warm deformation, the equiaxed ferrite grains in the local regions with bulky austenite (marked by circles) are with large misorientation between each other and those in the regions without bulky austenite (marked by boxes) are with small misorientation, showing that the ferrite dynamic recrystallization is related to the formation of bulky austenite grains.

For the $3.6 \mathrm{ks}$ pre-tempered specimen, the austenite grains appear at the prior austenite grain boundaries, the martensite packet boundaries and the martensite block boundaries. After the $\varepsilon=0.6$ warm compression, the ferriteaustenite duplex microstructure becomes fully equiaxed and the volume fraction of austenite increases from $18 \%$ before deformation to $36.8 \%$ after deformation (Figs. 6,7 ) and the average size of austenite grains decreases from $1.53 \mu \mathrm{m}$ before deformation to $0.94 \mu \mathrm{m}$ after deformation (Table 2), which also proves that the warm deformation promotes the precipitation of ultrafine grained austenite. Meanwhile, the
Table 2. Comparison between average grain sizes before and after warm compression $(\mu \mathrm{m})$.

\begin{tabular}{cccccc}
\hline \multirow{2}{*}{ Symbol } & \multirow{2}{*}{ Pre-tempering } & \multicolumn{2}{c}{ Before compression } & \multicolumn{2}{c}{ After compression } \\
\cline { 2 - 6 } & & Ferrite & Austenite & Ferrite & Austenite \\
\hline \multirow{2}{*}{$18 \mathrm{Ni}$} & No & 6.6 & - & $1.3\left(1.6^{*}\right)$ & - \\
\cline { 2 - 6 } & $3.6 \mathrm{ks}, 843 \mathrm{~K}$ & 6.4 & - & $1.2\left(1.8^{*}\right)$ & - \\
\hline \multirow{3}{*}{$17 \mathrm{Ni}-0.2 \mathrm{C}$} & No & 4.7 & 1.8 & 1.5 & 0.62 \\
\cline { 2 - 6 } & $3.6 \mathrm{ks}, 773 \mathrm{~K}$ & 2.8 & 1.5 & 0.85 & 0.94 \\
\cline { 2 - 6 } & $36 \mathrm{ks}, 773 \mathrm{~K}$ & 1.6 & 2.3 & 1.7 & 0.61 \\
\hline
\end{tabular}

Note: Austenite grain sizes of $18 \mathrm{Ni}$ specimens were not analyzed because of low thermal stabilization; $18 \mathrm{Ni}$ specimens were compressed at $843 \mathrm{~K}, \varepsilon=0.8$ (*means $\varepsilon=0.6$ ), $8.3 \times 10^{-4}$ and $17 \mathrm{Ni}-0.2 \mathrm{C}$ specimens were compressed at $773 \mathrm{~K}, \varepsilon=0.6$, $8.3 \times 10^{-4}$.

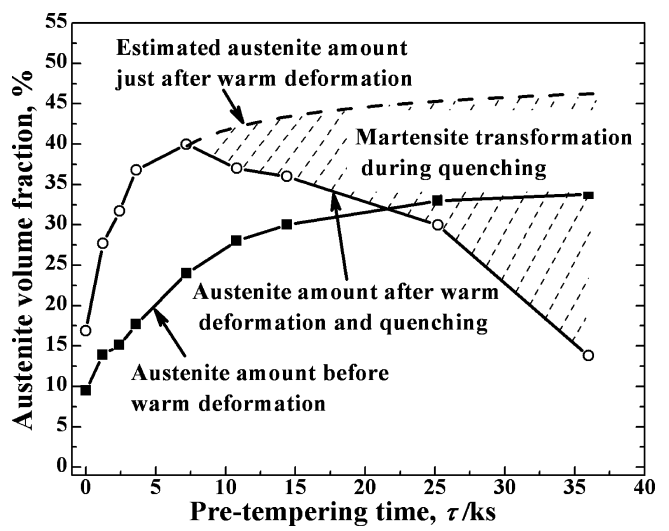

Fig. 7. Change in austenite amount of $17 \mathrm{Ni}-0.2 \mathrm{C}$ steel by pretempering and warm deformation according to EBSD phase mapping statistics.

average grain size of ferrite changes from $2.77 \mu \mathrm{m}$ before deformation to $0.85 \mu \mathrm{m}$ after deformation (Table 2), which is smaller than that of $3.6 \mathrm{ks}$ pre-tempered $18 \mathrm{Ni}$ steel after warm compression at a strain of 0.8 (Table 2) and reveals that the higher $Z$-value $(17 \mathrm{Ni}-0.2 \mathrm{C}, 773 \mathrm{~K}, Z=1.21 \times$ $\left.10^{14} \mathrm{~s}^{-1} ; 18 \mathrm{Ni}, 843 \mathrm{~K}, Z=4.55 \times 10^{12} \mathrm{~s}^{-1}\right)$ and high carbon content are helpful to refine the fully recrystallized microstructure. The grain size statistics of two investigated steels after full recrystallization (Fig. 8) reveal the size distributions of ferrite and austenite are relatively centralized and no marked phenomenon of mixed coarse-fine grains exists in these microstructures.

When the pre-tempering time prolongs to $36.0 \mathrm{ks}$, the austenite amount approaches $33.8 \%$ (Figs. 6, 7). After the $\varepsilon=0.6$ warm deformation, the ferrite grains are elongated and coarse, showing that the dynamic recrystallization is delayed evidently. Meanwhile, the austenite amount measured at room temperature decreases abruptly to $13.8 \%$. According to the phase diagram calculated by using the THERMO-CALC Fe-DATA (Ver. 3) database (Fig. 1), the equilibrium microstructure at $773 \mathrm{~K}$ consists of ferrite, austenite and cementite. As shown in Fig. 7, the austenite amount increases gradually due to the austenite precipitation during long-time pre-tempering at an elevated temperature below the austenite transformation starting temperature, which is consistent with the previous reports for a $\mathrm{Fe}-\mathrm{Ni}$ martensite alloy ${ }^{21)}$ and for a $18 \mathrm{Ni}-12 \mathrm{Co}-4 \mathrm{Mo}$ maraging steel. ${ }^{22)}$ The decreasing austenite amount after warm compression is related to the weakening of austenite 

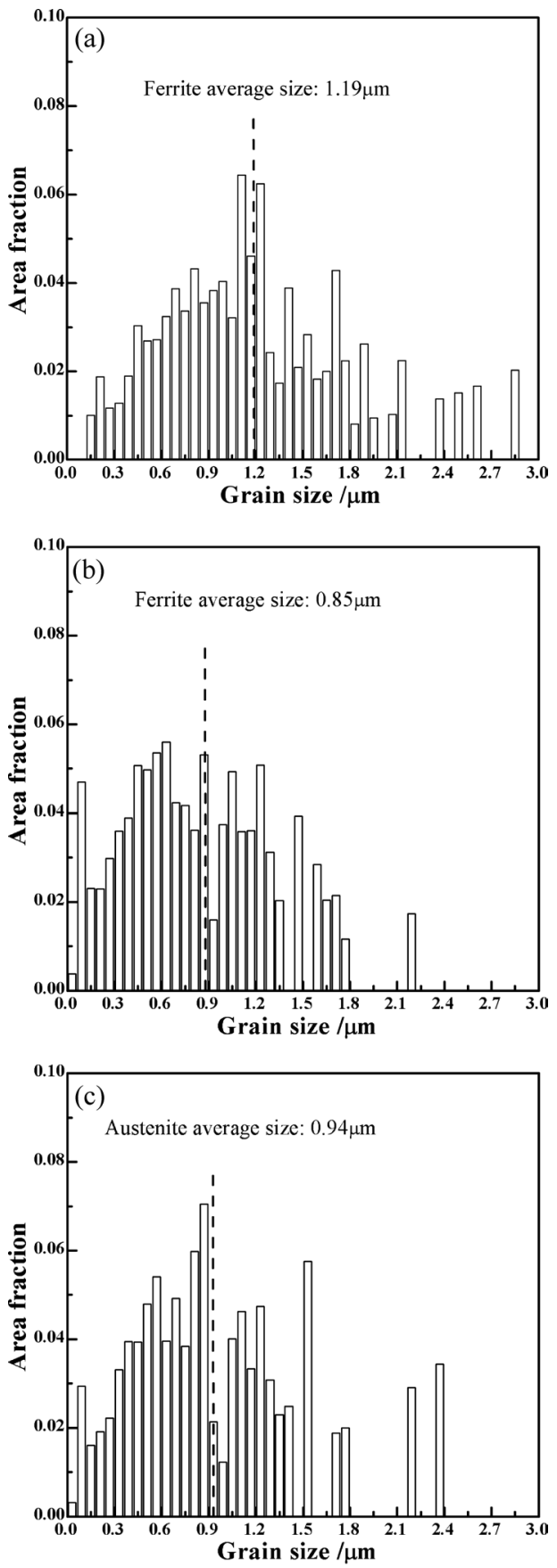

Fig. 8. Grain size distributions of $18 \mathrm{Ni}$ and $17 \mathrm{Ni}-0.2 \mathrm{C}$ steels after $3.6 \mathrm{ks}$ pre-tempering treatment and warm compression: (a) $18 \mathrm{Ni}$, ferrite, $\varepsilon=0.8,843 \mathrm{~K}, 8.3 \times 10^{-4} / \mathrm{s}$; (b) $17 \mathrm{Ni}-0.2 \mathrm{C}$, ferrite, $\varepsilon=0.6,773 \mathrm{~K}, 8.3 \times 10^{-4} / \mathrm{s}$; (c) $17 \mathrm{Ni}-$ $0.2 \mathrm{C}$, austenite, $\varepsilon=0.6,773 \mathrm{~K}, 8.3 \times 10^{-4} / \mathrm{s}$.

thermal stability caused by the carbon depletion in austenite after cementite precipitation. Since the cementite particles are mostly in nanometer scale, TEM observations are necessary to confirm this interpretation.

\subsection{TEM Microstructure Observation and EDX Com- position Analysis}

Figure 9 shows the bright field images for the non-tempered and pre-tempered microstructures of $18 \mathrm{Ni}$ steel after warm compression. In the non-tempered and warm compressed specimen ( $\varepsilon=0.6$, Fig. $9(\mathrm{a})$ ), both the non-recrystallized ferrite grains with high density of dislocations and the equiaxed ferrite grains with low density of dislocations

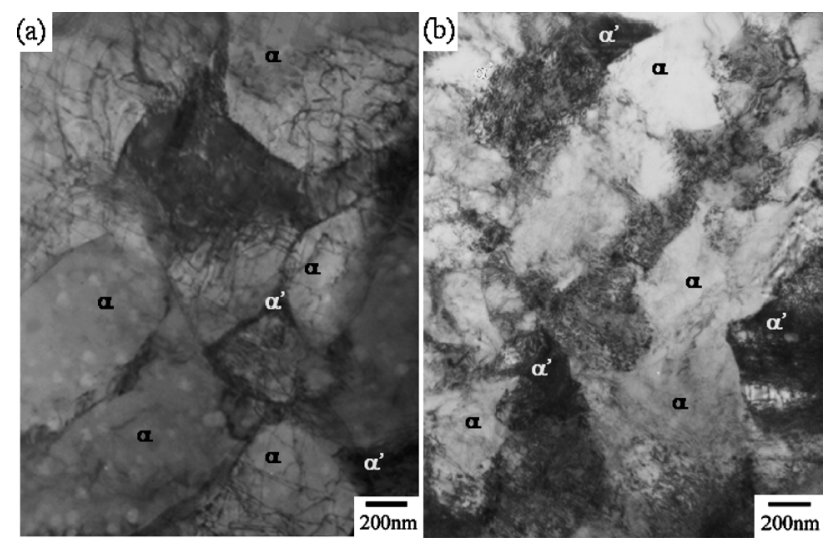

Fig. 9. TEM microstructures in the non-tempered (a) and $3.6 \mathrm{ks}$ pre-tempered (b) specimens of $18 \mathrm{Ni}$ steel after warm compression at $843 \mathrm{~K}, \varepsilon=0.6,8.3 \times 10^{-4} / \mathrm{s}$, bright images. Here, $\alpha$ and $\alpha^{\prime}$ denote ferrite and martensite, respectively.

Table 3. Nickel concentrations in ferrite matrix and secondphase austenite/martensite of $3.6 \mathrm{ks}$ pre-tempered and warm deformed specimens (mass \%).

\begin{tabular}{rllll}
\hline Symbol & Ferrite matrix & Second-phase austenite/martensite \\
\hline \multirow{3}{*}{$18 \mathrm{Ni}$} & No.1 & $18.0^{* 1}$ & No.1 & 19.1 \\
\cline { 2 - 5 } & No.2 & $17.8^{* 2}$ & No.2 & 20.0 \\
\cline { 2 - 5 } & No.3 & $17.8^{* 2}$ & No.3 & 22.2 \\
\hline \multirow{3}{*}{17 Ni-0.2C Co. 2} & 16.5 & No.1 & 25.4 \\
\cline { 2 - 5 } & No. & 15.5 & No.2 & 19.9 \\
\hline & No.3 & 15.7 & No.3 & 26.5 \\
\hline
\end{tabular}

Note: $* 1$, near second-phase martensite particle; $* 2$, far from second-phase martensite particle.

can be found frequently. The black particles are confirmed to be the martensite related to the metastable austenite. In the $3.6 \mathrm{ks}$ pre-tempered and warm compressed specimen $(\varepsilon=0.6$, Fig. 9(b)), the new equiaxed ferrite grains appear around the martensite particles but the grain boundaries between them are usually of small-angle boundaries. It suggests that a larger strain is necessary to realize the full recrystallization, which is consistent with the corresponding EBSD results (Fig. 5).

Figure 10 shows the $3.6 \mathrm{ks}$ pre-tempered $17 \mathrm{Ni}-0.2 \mathrm{C}$ microstructures after warm compression. The ultrafine equiaxed ferrite and austenite grains can be found frequently (Fig. 10(a)), suggesting that the warm deformation promotes the austenite precipitation and the ferrite dynamic recrystallization. In Fig. 10(b), the twin martensite is observed in the foil polished at $223 \mathrm{~K}$, revealing the carbon content in the prior austenite is not low. The misorientation analysis confirms that the grain boundaries between these grains and their neighbors are of high angle boundaries (marked by thicklines, Fig. 10(c)). Considering the random orientation characteristics of equiaxed ferrite grains as shown in Fig. 6, the dynamic recrystallization of ferrite can be confirmed really to take place during the warm deformation.

According to the equilibrium phase diagrams (Fig. 1), the nickel-rich austenite should appear at $843 \mathrm{~K}$ in $18 \mathrm{Ni}$ and the nickel- and carbon-rich austenite and cementite should appear at $773 \mathrm{~K}$ in $17 \mathrm{Ni}-0.2 \mathrm{C}$. The EDX composition analysis (Table 3) proves that the metastable austenite (or martensite) grains are nickel-enriched, for example, the 
nickel content is about 20-26 mass\% (austenite) versus $15-16$ mass $\%$ (ferrite) in $17 \mathrm{Ni}-0.2 \mathrm{C}$. Though the EDX analysis can not provide a reliable carbon concentration in the constituent phases, the austenite in the $3.6 \mathrm{ks}$ pre-tempered $17 \mathrm{Ni}-0.2 \mathrm{C}$ after warm compression should be carbon-enriched because (a) no cementite particles are found in such microstructure, (b) the stability of austenite phase is higher than that in $18 \mathrm{Ni}$, (c) the diffusion of carbon is more rapid than that of nickel and (d) the interstitial solubility of carbon is much higher in austenite than in ferrite. Considering that the $3.6 \mathrm{ks}$ pre-tempering decreases the dislocation density of martensite substructures, the accelerated dy-

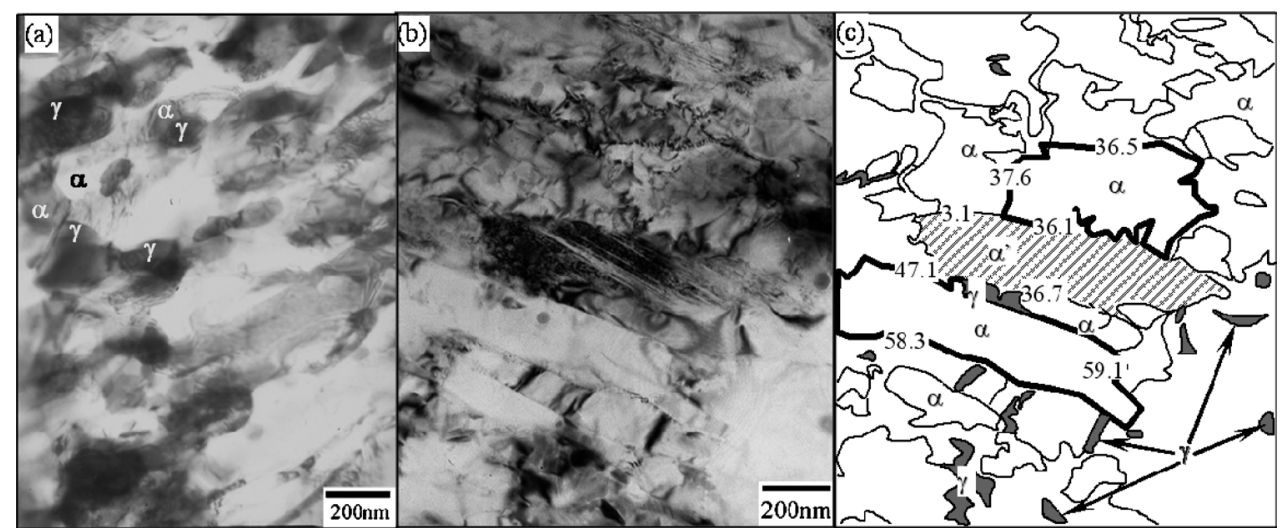

Fig. 10. TEM microstructures in the $3.6 \mathrm{ks}$ pre-tempered specimens of $17 \mathrm{Ni}-0.2 \mathrm{C}$ steel after warm compression at $773 \mathrm{~K}, \varepsilon=0.6,8.3 \times 10^{-4} / \mathrm{s}$ : (a) twin-jet polished at room temperature; (b, c) twin-jet polished at $223 \mathrm{~K}$. The gray grains (or $\gamma$ ), the patched grain (or $\alpha^{\prime}$ ) and the white grains (or $\alpha$ ) denote the austenite, the martensite and the ferrite, respectively. The misorientation angle values between neighboring grains are given on the corresponding boundaries. The thick-line surrounded grains are recrystallized ones.
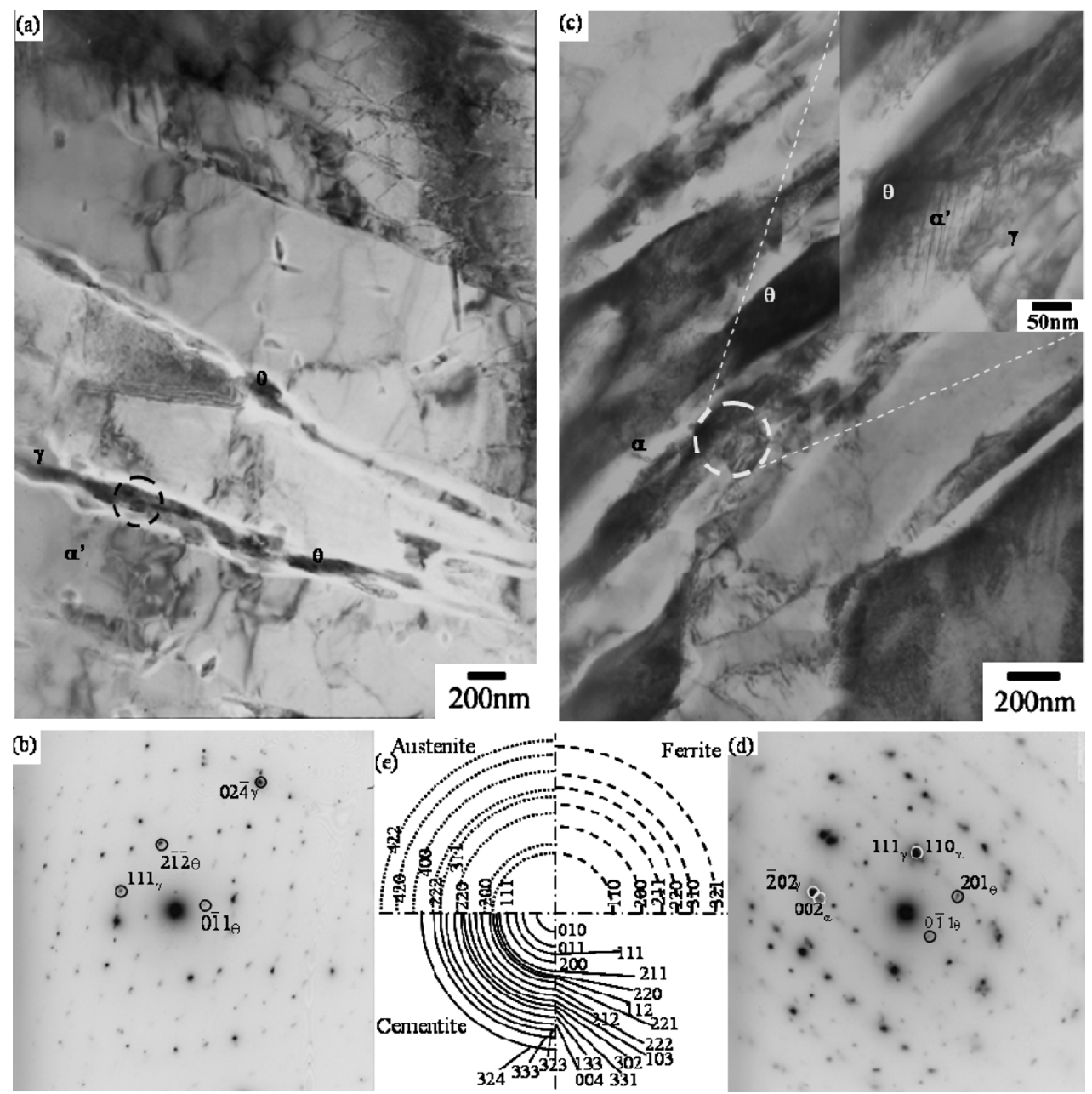

Fig. 11. TEM microstructures $(a, c)$ and selected area diffraction patterns $(b, d)$ taken from the dash line marked region in the $36 \mathrm{ks}$ pre-tempered specimens of $17 \mathrm{Ni}-0.2 \mathrm{C}$ steel before $(\mathrm{a}, \mathrm{b})$ and after $(\mathrm{c}, \mathrm{d})$ warm compression at $773 \mathrm{~K}, \varepsilon=0.6,8.3 \times 10^{-4} / \mathrm{s}$, twin-jet polished at $223 \mathrm{~K}$, where $\gamma, \alpha, \theta$ and $\alpha^{\prime}$ denote austenite, ferrite, cementite and martensite, respectively; (e) schematic illustration for diffraction rings and indexes for austenite, ferrite and cementite. 
namic recrystallization is mainly related to the formation of a large amount of carbon-enriched austenite.

Figure 11 shows the TEM bright field images and selected area diffraction patterns obtained from the $36 \mathrm{ks}$ pretempered specimens before and after warm compression. Since the diffraction pattern was taken from several multiphase ultrafine grains, it is too complex to label exact $(h k l)$ index for each spot. Figure 11(e) schematically gives their diffraction rings and indexes (for cementite, some low index rings are omitted because of curve overlapping), where lattice constants are assumed to be $0.2861 \mathrm{~nm}$ for ferrite, $0.3570 \mathrm{~nm}$ for austenite ${ }^{23)}$ and $a=0.4521 \mathrm{~nm}, b=0.5079$ $\mathrm{nm}, c=0.6747 \mathrm{~nm}$ for cementite. ${ }^{24)}$ These microstructures are confirmed to consist of ferrite, austenite and cementite.

In case of the $36 \mathrm{ks}$ tempering, the elongated martensite laths within low dislocation density are clearly observed, which is related to the recovery of martensite (Fig. 11(a)). It is also found that the cementite precipitates preferably around the carbon-enriched austenite grains located at the martensite lath boundaries rather than within the martensite laths. The warm deformation accelerates the carbon diffusion and promotes the dynamic precipitation of spherical cementite particles within the martensite laths (Fig. 11(c)). For a pre-tempering time longer than $7.2 \mathrm{ks}$, the carbon partitioning from martensite to austenite is gradually replaced by the cementite precipitation. Because of the precipitation of cementite particles and the increase of austenite amount, the average carbon concentration in austenite must decrease, finally lower than that in the $3.6 \mathrm{ks}$ tempered and deformed specimen. As a result, the thermal stability of austenite decreases, some austenite grains transform to martensite upon cooling after deformation and the fresh nanometer-scale martensite particles form around the cementite and austenite particle (Fig. 11(c)). Hence the austenite amount after rapid cooling to room temperature becomes smaller (see Fig. 7). The low dislocation density and no carbon-enriched austenite lead to the delayed dy- namic recrystallization in the $36 \mathrm{ks}$ pre-tempered and warm compressed specimen when compared with the $3.6 \mathrm{ks}$ pretempered and warm compressed specimen.

\subsection{Effects of Volume Fraction and Carbon Concen- tration in Austenite on Dynamic Recrystallization Behavior}

The in situ neutron diffraction study about $3.6 \mathrm{ks}$ pretempered $17 \mathrm{Ni}-0.2 \mathrm{C}$ steel $^{20)}$ has shown that the heterogeneous deformation occurs during warm compression and the ferrite matrix is subject to larger plastic deformation than the carbon-enriched austenite, i.e. the former is softer than the latter. In addition, it is also found that the gradually decreased austenite carbon concentration due to austenite dynamic precipitation weakens the difference in hardness between austenite particles and ferrite matrix.

Figure 12 illustrates the influences of volume fraction and carbon concentration in austenite on the heterogeneous deformation and the ferrite-austenite duplex microstructure evolution. For the carbon-added high-nickel steel, $17 \mathrm{Ni}-$ $0.2 \mathrm{C}$, the amount of carbon-enriched austenite increases due to the proper pre-tempering and the austenite particles becomes harder than the ferrite matrix. Hence the larger local plastic flow takes place in the regions around austenite particles. When the local plastic strain increases to a critical value $\left(\varepsilon=\varepsilon_{1}\right)$, the recrystallized ferrite grains preferably nucleate in these local regions near the austenite particles according to the related recrystallization model. ${ }^{25)}$ When the true strain increases to another critical value $\left(\varepsilon=\varepsilon_{2}\right)$, all the ferrite grains are equiaxed and recrystallized (Fig. 12(b)).

In case of no pre-tempering, the austenite amount is relatively less than that in case of $3.6 \mathrm{ks}$ pre-tempering and the carbon content in austenite is lower than that in the latter. Although the warm compression promotes the austenite precipitation and the carbon enrichment in austenite, the plastic deformation partitioning between austenite particles and ferrite matrix is a little weaker. Consequently, at the

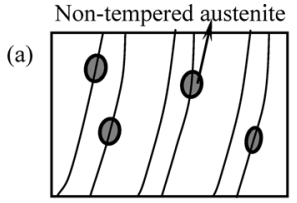

No deformation

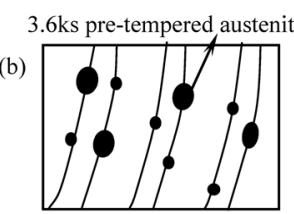

No deformation

(c)

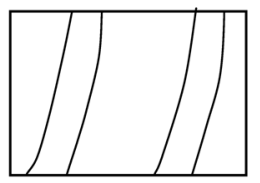

No deformation

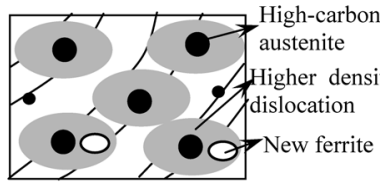

$\varepsilon=\varepsilon_{1}$
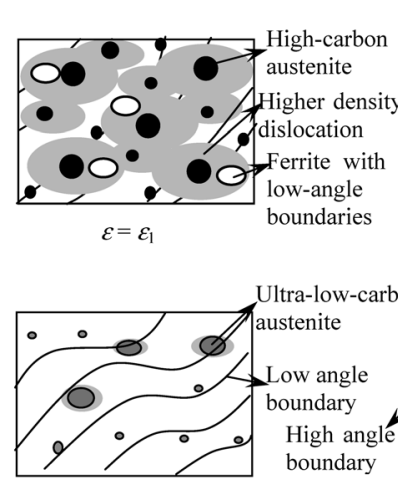

$\varepsilon=\varepsilon_{1}$

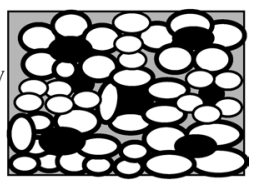

$\varepsilon=\varepsilon_{2}$

Ferrite with high-angle

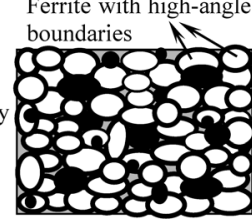

$\varepsilon=\varepsilon_{2}$

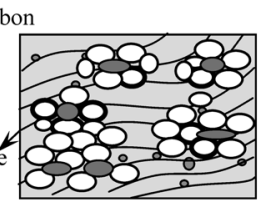

$\varepsilon=\varepsilon_{2}$

Fig. 12. Schematic illustration for microstructure evolution of martensite steels with different carbon contents during warm deformation, where the compression axis is along the vertical direction and $\varepsilon_{1}<\varepsilon_{2}$ (see text): (a) $17 \mathrm{Ni}-0.2 \mathrm{C}$, non-tempered, at $773 \mathrm{~K}$; (b) $17 \mathrm{Ni}-0.2 \mathrm{C}, 3.6 \mathrm{ks}$ pre-tempered, at $773 \mathrm{~K}$; (c) $18 \mathrm{Ni}$, at $843 \mathrm{~K}$. 
true strains $\varepsilon=\varepsilon_{2}$, the recrystallized ferrite amount is correspondingly less than that in the case of $3.6 \mathrm{ks}$ pre-tempering (Fig. 12(a)).

When the pre-tempering time is extended to more than $14.4 \mathrm{ks}$, the precipitation of cementite particles leads to evident carbon depletion in austenite, and the plastic deformation partitioning between the austenite and the recovered ferrite matrix is no longer apparent. Hence the dynamic recrystallization of ferrite is retarded markedly. ${ }^{26)}$ The coarse austenite grains formed during long-time pre-tempering are metastable because of low carbon concentration, easy to deform during warm compression, and then transform into martensite (or ferrite matrix) upon rapid cooling to room temperature.

For the ultra-low-carbon high-nickel steel, $18 \mathrm{Ni}$, since the carbon-enriched austenite is impossible to form in such steel and since the martensite is easy to recover, the plastic deformation partitioning is relatively weak. Moreover, the dislocation density in the martensite matrix is lower than that in $17 \mathrm{Ni}-0.2 \mathrm{C}$ steel and the block size is also coarser. As a result, a larger compressive strain is needed for the full recrystallization (Fig. 12(c)).

\section{Conclusions}

The microstructures of warm compressed high-nickel martensite steels with different carbon contents were comparably investigated with a field-emission scanning electron microscope attached with an electron backscattering diffraction equipment (FE-SEM/EBSD) and a transmission electron microscope attached with an energy dispersive $\mathrm{X}$ ray spectroscope (TEM/EDX). The following main results were obtained.

(1) The carbon addition is beneficial to reduce the critical strain for full recrystallization of high-nickel martensite steels during warm compression.

(2) The increment of carbon-enriched austenite volume fraction accelerates the dynamic recrystallization of ferrite through plastic deformation partitioning in the $17 \mathrm{Ni}-0.2 \mathrm{C}$ steel.

(3) Proper pre-tempering promotes the precipitation of the carbon- and nickel-enriched austenite, and then promotes the dynamic recrystallization in the $17 \mathrm{Ni}-0.2 \mathrm{C}$ steel. On the other hand, long-time tempering leads to the carbon depletion in austenite so as to delay the dynamic recrystallization.

(4) In the $18 \mathrm{Ni}$ steel, a higher warm compression strain is required for full recrystallization during warm compression, mainly because of no carbon-enriched austenite.

\section{Acknowledgement}

The authors thank Honda R\&D Co., LTD. for financial support.

\section{REFERENCES}

1) G. Glovre and C. M. Selllers: Metall. Mater. Trans., 4 (1973), 765.

2) T. Maki, S. Okaguchi and I. Tamura: Proc. 6th Int. Conf. on Strength of Metals and Alloys (ICSMA 6), Pergamon Press, New York, (1982), 529.

3) A. Najafi-Zadeh, J. J. Jonas and S. Yue: Metall. Trans. A, 23A (1992), 2607.

4) N. Tsuji, Y. Matsubara, Y. Saito and T. Maki: J. Jpn. Inst. Met., 62 (1998), 967.

5) A. Ohmori, S. Torizuka, K. Nagai, N. Koseki and Y. Kogo: Mater. Trans., 45 (2004), 2224.

6) N. Tsuji, S. Okuno, Y. Koizumi and Y. Minamino: Mater. Trans., 45 (2004), 2272.

7) R. L. Miller: Metall. Mater. Trans., 3 (1972), 905.

8) K. Ameyama, N. Matsumura and M. Tokizane: J. Jpn. Soc. Heat Treat., 28 (1988), 233.

9) R. Ueji, N. Tsuji N, Y. Minamino and Y. Koizumi: Acta Mater, 50 (2002), 4177.

10) T. Hayashi, S. Torizuka, T. Mitsui, K. Tsuzaki and K. Nagai: CAMPISIJ, 11 (1998), 1031.

11) Y. Z. Bao, Y. Adachi, Y. Toomine, P. G. Xu, T. Suzuki and Y. Tomota: Scr. Mater., 53 (2005), 1471.

12) Y. Z. Bao, Y. Adachi, Y. Toomine, T. Suzuki, P. G. Xu and Y. Tomota: Tetsu-to-Hagané, 91 (2005), 602.

13) T. Furuhara, T. Yamaguchi, S. Furimoto and T. Maki: Mater. Sci. Forum, 539-543 (2007), 155.

14) J. H. Li, P. G. Xu, Y. Tomota and Y. Adachi: ISIJ Int., 48 (2008), 1008 .

15) B. Poorganji, T. Yamaguchi, G. Miyamoto, T. Furuhara and T. Maki: Scr. Mater., 59 (2008), 279

16) P. G. Xu, B. Z. Bai, F. X. Yin, H. S. Fang and K. Nagai: Mater. Sci. Eng. A, 385 (2004), 65

17) Y. Tomota, A. Narui and N. Tsuchida: ISIJ Int., 48 (2008), 1107.

18) P. G. Xu and Y. Tomota: Acta Metall. Sin., 42 (2006), 681.

19) P. G. Xu and Y. Tomota: Heat Treatment (Shanghai), 21 (2006), No. 4, 1.

20) P. G. Xu, Y. Tomota and E. C. Oliver: ISIJ Int., 48 (2008), 1618.

21) M. Enomoto and E. Furubayashi: Trans. JIM, 18 (1977), 817.

22) M. Moriyama, S. Takaki and N. Kawagoishi: J. Jpn. Soc. Heat Treat., 41 (2001). 266

23) P. G. Xu, Y. Tomota, P. Lukas, O. Muransky and Y. Adachi: Mater. Sci. Eng. A, 435 (2006), 46.

24) R. C. Reed and J. H. Root: Scr. Mater, 38 (1998), 95.

25) R. D. Doherty, D. A. Hughes, F. J. Humphreys, J. J. Jonas, D. Juul Jensen, M. E. Kassner, W. E. King, T. R. McNelley, H. J. McQueen and A. D. Rollett: Mater. Sci. Eng. A, 238 (1997), 219.

26) T. Maki, T. Furuhara and K. Tsuzaki: ISIJ Int., 41 (2001), 571 